\title{
Des modèles murins de maladies inflammatoires cryptogénétiques de l'intestin obtenus par mutagenèse de gènes codant pour des composants du système immunitaire
}

Le numéro double de médecine/sciences (n० 8-9, vol. 9, août/septembre 1993) était en partie consacré aux maladies inflammatoires cryptogénétiques de l'intestin. Des articles traitant de ces affections, il ressortait que l'on ne pouvait guère que formuler des hypothèses quant à leurs mécanismes. Il semble bien que ce numéro et ces articles aient été publiés quelques mois trop tôt. En effet, une remarquable efflorescence de résultats publiés dans un numéro de Ciell daté du 22 octobre indique que différents types de perturbations du système immunitaire obtenues chez la souris grâce à la mutagenèse insertionnelle par recombinaison homologue s'accompagnent de maladies inflammatoires de l'intestin, notamment de maladies ressemblant à la rectocolite hémorragique. $\mathrm{B}$. Mombaerts et al., du laboratoire de $S$. Tonegawa (Boston, MA, USA) rapportent que des lésions de ce type sont observées chez des souris homozygotes pour l'inactivation des gènes codant pour les chaînes $\alpha$, les chaines $\beta$ et, à la fois, les chaînes $\beta$ et $\delta$ du récepteur pour l'antigène des lymphocytes $\mathrm{T}(\mathrm{T} c \mathrm{R})$. De mêmes symptômes sont observés en cas de déficit touchant les molécules de classe II du complexe majeur d'histocompatibilité. Tous ces animaux ont un déficit profond de l'immunité cellulaire, mais possèdent des lymphocytes B et une réponse humorale. En revanche, les souris dont les gènes RAG-2 ont été inactivés, atteintes d'un déficit combiné sévère touchant à la fois l'immunité cellulaire et l'immunité humorale, ne développent pas de maladies inflammatoires de l'intestin [1]. B. Sadlack et al., de Würzburg et Lübeck (Allemagne), décrivent, chez des souris déficientes en IL.2 par mutagenèse insertionnelle du gène, une affection semblant éga- lement proche de la rectocolite hémorragique. Dans ce cas, le déficit de l'immunité cellulaire est limité et principalement marqué par un déséquilibre entre les cellules Thl (T-helper 1), déficientes, et les cellules Th2, hyperactives. Les cellules Th2 sécrètent l'interleukine 4 et leur hyperactivité est associée à une stimulation non contrôlée des lymphocytes B. D'ailleurs, ces animaux développent plusieurs types d'autoanticorps [2]. Dans ces modèles, nous retrouvons un point commun, la persistance ou l'activation des cellules lymphocytaires B, alors qu'existe un déficit ou un déséquilibre des cellules T. On peut ainsi proposer que l'atteinte inflammatoire de l'intestin serait due à l'apparition d'autoanticorps synthétisés par des lymphocytes B en l'absence de cellules T suppressives, et (ou) d'un contrôle négatif exercé par la population Thl. En revanche, un troisième modèle décrit par Kühn et al. de Cologne, Hambourg (Allemagne) et Palo Alto (CA, USA) se présente de manière cliniquement et immunologiquement différente. Ici, l'inactivation homozygote du gène de l'interleukine 1() est associée à une entérocolite chronique intéressant la totalité de l'intestin, avec une hyperplasie de la muqueuse, des réactions inflammatoires et une expression aberrante des molécules de classe II du complexe majeur d'histocompatibilité par les cellules de l'épithélium intestinal. Ces lésions sont particulièrement sévères, conduisant à un retard de croissance et à une anémie par hémorragie chronique chez des animaux élevés dans des conditions normales alors que l'élevage en conditions «sans germes" limite les lésions à une inflammation colique. L'IL.10 joue normalement un rôle suppresseur sur les cellules Thl et les macro- phages. De ce fait, les souris IL.10 ${ }^{-}$ présentent une hyper-réactivité des lymphocytes Thl avec, notamment, hypersécrétion de l'interféron $\gamma$. Les lésions pourraient être dues, ici aussi, à une réponse anormale des lymphocytes B à des antigènes portés par des germes intestinaux; alternativement, une réponse inflammatoire anormale des macrophages, non contrôlée par l'IL10, pourrait être impliquée [3]. Ce qui est remarquable dans ces différents articles, c'est la limitation à l'intestin des signes inflammatoires d'animaux présentant, par ailleurs, des perturbations plus ou moins graves de leur système immunitaire. Cela peut témoigner de l'extraordinaire complexité des réactions immunologiques au niveau de l'intestin, qui est en contact avec une très grande diversité d'antigènes alimentaires et bactériens. Ces résultats suggèrent que les maladies inflammatoires cryptogénétiques de l'intestin pourraient être d'étiologies en réalité extrêmement diverses, de nombreux déséquilibres du système immunitaire se manif estant par une perturbation des systèmes de régulation de la réponse immune aux antigènes intestinaux [4].

A.K.

1. Mombaerts B, Mizoguchi E, (irusby MJ, (ilimcher L.H, Bhan AK, Tonegawa S. Spontaneous development of inflammatory bowel disease in T cells receptor mutant mice. Cell $1993 ; 75: 275-82$

2. Sadlack B, Merz H, Schorle H, Schimpl A, Feller AC, Horak I. Ulcerative colitis-like disease in mice with a clisrupted interleukin-2 gene. Cell 199.3; 75 : 2:53-61

3. Kühn R, Löhler J, Raemnick D, Rajewskw K, Müller W. Interleukine-1()-deficient mice develop chronic enterocolitis. (ell 19933; 75 : $26.3-74$ 4. Strober $W^{\prime}$, Ehrhardt RO. Chronic intestinal inflammation : an unexpected outcome in crtokine or T cell receptor mutant mice. Cell $1993 ; 75: 203-5$. 